\title{
Identification of the pivotal role of SPP1 in kidney stone disease based on multiple bioinformatics analysis
}

\author{
Sen-Yuan Hong ${ }^{\dagger}$, Qi-Dong Xia ${ }^{\dagger}$, Jin-Zhou Xu, Chen-Qian Liu, Jian-Xuan Sun, Yang Xun ${ }^{*}$ and Shao-Gang Wang ${ }^{*}$
}

\begin{abstract}
Background: Kidney stone disease (KSD) is a multifactorial disease involving both environmental and genetic factors, whose pathogenesis remains unclear. This study aims to explore the hub genes related to stone formation that could serve as potential therapeutic targets.

Methods: Based on the GSE73680 dataset with 62 samples, differentially expressed genes (DEGs) between Randall's plaque (RP) tissues and normal tissues were screened and weighted gene co-expression network analysis (WGCNA) was applied to identify key modules associated with KSD. Gene Ontology (GO) and Kyoto Encyclopedia of Genes and Genomes (KEGG) enrichment analysis were performed to explore the biological functions. The protein-protein interaction (PPI) network was constructed to identify hub genes. Meanwhile, CIBERSORT and sSGSEA analysis were used to estimate the infiltration level of the immune cells. The correlations between hub genes and immune infiltration levels were also investigated. Finally, the top hub gene was selected for further GSEA analysis.
\end{abstract}

Results: A total of 116 DEGs, including 73 up-regulated and 43 down-regulated genes, were screened in the dataset. The red module was identified as the key module correlated with KSD. 53 genes were obtained for functional enrichment analysis by taking the intersection of DEGs and genes in the red module. GO analysis showed that these genes were mainly involved in extracellular matrix organization (ECM) and extracellular structure organization, and others. KEGG analysis revealed that the pathways of aldosterone-regulated sodium reabsorption, cell adhesion molecules, arachidonic acid (AA) metabolism, and ECM-receptor interaction were enriched. Through PPI network construction, 30 hub genes were identified. CIBERSORT analysis revealed a significantly increased proportion of MO macrophages, while sSGSEA revealed no significant differences. Among these hub genes, SPP1, LCN2, MMP7, MUC1, SCNN1A, CLU, SLP1, LAMC2, and CYSLTR2 were positively correlated with macrophages infiltration. GSEA analysis found that positive regulation of JNK activity was enriched in RP tissues with high SPP1 expression, while negative regulation of IL-1 $\beta$ production was enriched in the low-SPP1 subgroup.

Conclusions: There are 30 hub genes associated with KSD, among which SPP1 is the top hub gene with the most extensive links with other hub genes. SPP1 might play a pivotal role in the pathogenesis of KSD, which is expected to become a potential therapeutic target, while its interaction with macrophages in KSD needs further investigation.

Keywords: Kidney stone disease, Weighted gene co-expression network analysis, Hub genes, SPP1, Macrophages

*Correspondence: tjxyang1993@163.com; sgwangtjm@163.com

†Sen-Yuan Hong and Qi-Dong Xia have contributed equally to this work Department of Urology, Tongji Hospital, Tongji Medical College, Huazhong University of Science and Technology, Wuhan, China

\section{Introduction}

Kidney stone disease (KSD) is one of the most common urological diseases worldwide with high incidence and recurrence rates, which contributes to a huge burden 
on the medical and health care system [1-3]. The most common type of stones is calcium oxalate $(\mathrm{CaOx})$ mixed with calcium phosphate $(\mathrm{CaP})$, accounting for approximately $80 \%$, followed by struvite, uric acid, and cysteine $[1,4]$. The most widely accepted theory of $\mathrm{CaOx}$ stone formation is Randall's plaque (RP) theory, in which stone can grow on the renal papillary surface attached to interstitial apatite deposits called RPs $[5,6]$. Although major advances in surgical techniques have greatly improved the effectiveness of stone removal, the exact mechanisms of stone formation and recurrence after surgery remain unclear, making the development of effective medical drugs stagnant.

Previous studies have discovered that several genes and their coded proteins were strongly linked with KSD, such as UMOD, MGP, SPP1, and so on [7]. SPP1, also known as osteopontin (OPN), is a secreted pleiotropic glycoprotein with diverse physiological and pathological functions [8]. As an important modulator of biomineralization, SPP1 is thought to be involved in stone formation, since RP is considered as a form of pathological biomineralization [9]. But previous studies showed that SPP1 played a dual role in promoting or inhibiting crystallization [10]. Therefore, there has been little agreement on the role of SPP1 in the pathogenesis of KSD. In addition, SPP1 is a chemical attractant for macrophages, which could regulate immune response through macrophages infiltration [8]. Recently, macrophage polarization is confirmed to play an important role in the development of KSD [11]. However, no study has investigated the relationship between SPP1 and macrophages in KSD, which needs to be fully explored.

For researchers, renal RP tissue is the key to exploring the underlying molecular mechanisms of KSD. The microarray study of the available gene expression profile of RP tissue (GSE73680) has linked many genes and pathways to KSD, but the analysis is relatively simple and a great deal of information has not been extensively mined [12]. This study was designed to investigate the GSE73680 dataset in greater depth through multiple bioinformatic methods to explore potential pathogenic genes and therapeutic targets. This study will use WGCNA for the first time to explore key modules significantly correlated with $\mathrm{KSD}$, screen hub genes in the protein-protein interaction (PPI) network, and evaluate immune infiltration levels in $\mathrm{RP}$ tissues by CIBERSORT and single-sample gene set enrichment analysis (ssGSEA). The correlations between hub genes and macrophages were also investigated. Finally, the top hub gene, SPP1, was selected for subsequent gene set enrichment analysis (GSEA).

\section{Methods \\ Data collection and preprocessing}

The flowchart of the study is shown in Fig. 1. The code used to perform the whole process was presented in Additional file 1. KSD related datasets were retrieved from the Gene Expression Omnibus (GEO) database (http://www.ncbi.nlm.nih.gov/geo/) using "kidney stone" as a search keyword. Two datasets (GSE73680 and GSE117518) which collected transcriptome data from RP papillary tissues and normal renal papillary tissues were

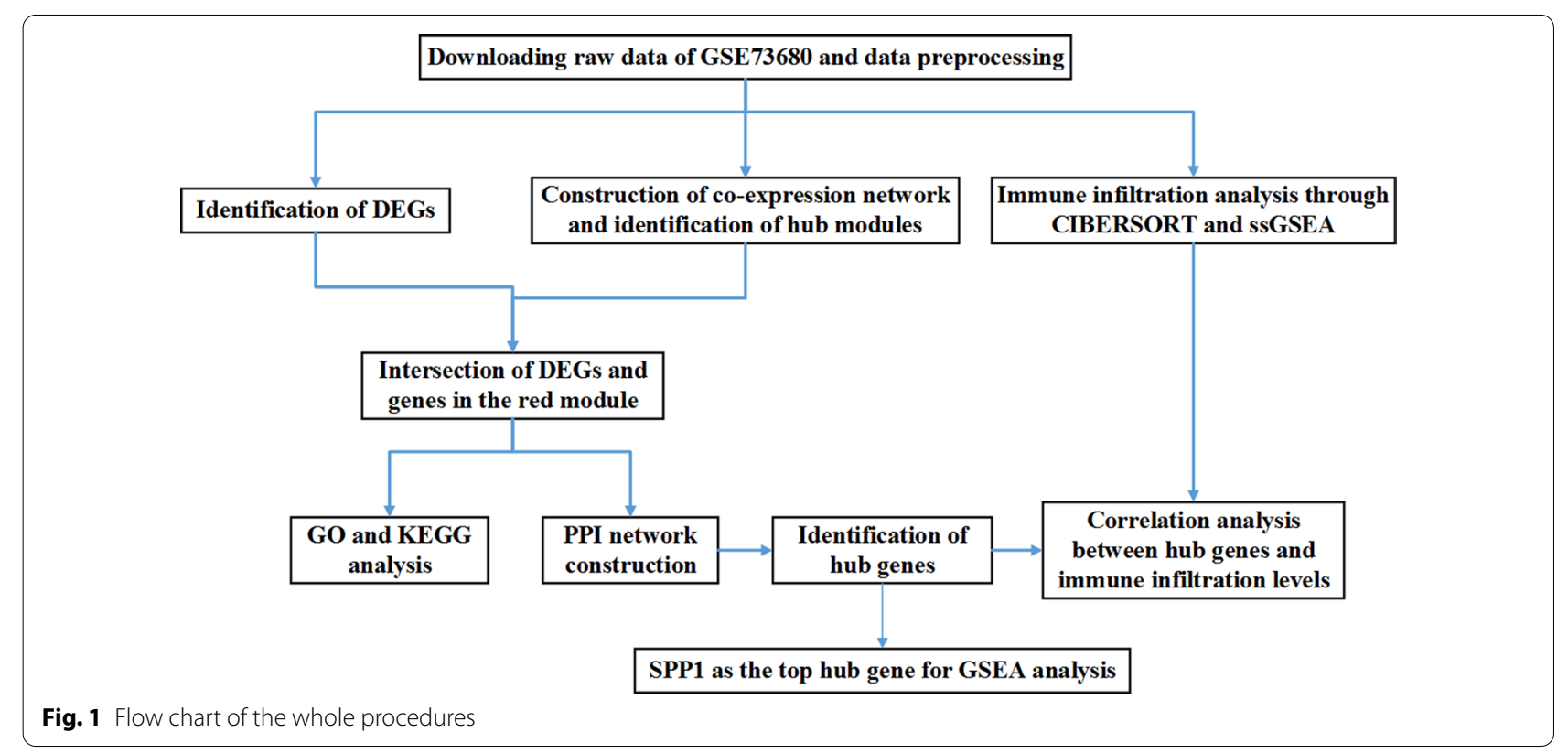


obtained. However, GSE117518 was excluded because of the small sample size (3 RP papillary tissues, 3 normal papillary tissues). Hence, GSE73680 was screened as an appropriate dataset for further analysis due to the relatively large sample size (29 RP papillary tissues and 33 normal papillary tissues).

The original raw data of each sample in GSE73680 was downloaded. As GSE73680 dataset was sequenced by Aglient microarray probe, the raw data was read by the "limma" package (version 3.48.3), the background of each sample was corrected by the "backgroundCorrect" function in "limma" package, and the data was normalized between different arrays by the "normalizeBetweenArrays" function in "limma" package [13]. The following steps were sequentially applied: removing the control probe, removing the probes that match no gene symbol, and removing the duplicated gene probes. Finally, the gene matrix was annotated according to the annotation files of the Agilent-039494 SurePrint G3 Human GE v2 $8 \times 60 K$ Microarray 039381 (Probe Name version) for further analysis.

\section{Identification of differentially expressed genes (DEGs)} GSE73680 dataset enrolled 62 renal papillary tissue samples, including 29 RP papillary tissues from stone formers, 27 normal papillary tissues from stone formers, and 6 normal papillary tissues from control patients. The "limma" package was used to identify DEGs between 33 normal papillary tissues and 29 RP papillary tissues with the threshold of false discovery rate $(\mathrm{FDR})<0.05$ and $\mid \log _{2}$ fold change (FC) $\mid>1$ [13]. The volcano plot of DEGs was drawn by the "ggplot2" package (version 3.3.5), and the heatmap of DEGs was generated using the "pheatmap" package (version 1.0.12) in the $\mathrm{R}$ software (version 4.1.1).

\section{Construction of a weighted co-expression network and identification of hub modules}

The "WGCNA" package (version 1.70.3) was applied to construct the co-expression networks and identify the disease-related hub modules [14]. First, the Pearson's correlation matrices were performed for all paired genes and a weighted adjacency matrix was constructed with the formula $a_{m n}=\left|c_{m n}\right|^{\beta} \quad\left(c_{m n}=\right.$ Pearson's correlation between gene $\mathrm{m}$ and gene $\mathrm{n} ; \mathrm{a}_{\mathrm{mn}}=$ adjacency between gene $m$ and gene $n$ ). Next, the soft-threshold power value that emphasizes strong correlations between genes and penalizes weak correlations was calculated and a suitable parameter $\beta$ was screened to build a scale-free network. Then, the weighted adjacency matrix was transformed into a topological overlap measure (TOM) matrix, which could measure the network connectivity of a gene defined as the sum of its adjacency with all other genes for the network generation [15]. After that, average linkage hierarchical clustering was conducted to classify genes with similar expression profiles into the same gene modules according to the TOM-based dissimilarity measure with a minimum size of 50 for the gene dendrogram [16]. The correlation between module eigengenes and clinical traits was assessed by Pearson correlation test to identify the significant modules. The KSD-related module was selected with the highest coefficient square $\left(\mathrm{R}^{2}\right)$ and the $P$ value $<0.05$.

\section{Functional and pathway enrichment analysis}

Following the steps above, two gene lists were obtained, one for the DEGs, the other one for the most KSDrelated gene modules. Subsequently, the intersection of these two gene lists was taken to identify the KSDrelated genes and a Venn diagram was constructed via the "VennDiagram" package (version 1.7.1). The Gene Ontology (GO) and the Kyoto Encyclopedia of Genes and Genomes (KEGG) pathways enrichment analysis were conducted to define the potential functions and pathways between these genes using the "org.Hs.eg.db" (version 3.10.0), "clusterProfiler" (version 3.14.3), "enrichplot" (version 1.6.1), and the "ggplot2" (version 3.3.5) packages in the $\mathrm{R}$ software $[17,18]$. The $\mathrm{GO}$ terms of biological processes (BP), molecular functions (MF), and cellular components $(\mathrm{CC})$ were respectively evaluated. Significant results were determined under the condition of adjusted $P$ value $<0.05$. The top ten terms were visualized if there were more than ten terms.

\section{Construction of protein-protein interaction (PPI) network and identification of hub genes}

The PPI network of the KSD-related genes was analyzed with the STRING database (http://string-db.org/) and visualized using Cytoscape software (version 3.8.2). To identify hub genes, the sides of each node were estimated and the genes were sorted based on the rank of the connection number of each gene. The top 30 genes with the largest edges connected to them were selected as hub genes and the gene rank 1st was identified as the top hub gene for further GSEA analysis.

\section{Immune infiltration analysis through CIBERSORT and SSGSEA}

For exploring the different infiltration degrees of immune cell types between RP tissues and normal tissues, the CIBERSORT algorithm was conducted to classify and quantify the abundance of 22 types of immune cells by $\mathrm{R}$ program [19]. The violin plot was generated using the "vioplot" package (version 0.3.7). Spearman correlation analysis was performed to examine the correlations between the hub genes and immune infiltrations. 
Meanwhile, the ssGSEA was used to estimate the infiltration levels of immune cells and immune-related functions in renal papillary tissues using the "GSVA" package (version 1.40.1) [20].

\section{Gene set enrichment analysis (GSEA)}

SPP1, the most connected node, was identified as the top hub gene for GSEA analysis. To further explore the role of SPP1 in KSD, 29 RP papillary tissues were divided into low- and high-expression groups by the median expression value of SPP1. Then GSEA analysis was applied to compare the differential enhanced functions or pathways between low- and high-SPP1 expression groups by GSEA software (version 4.1.0) [21]. The c5.go.v7.4.symbols. gmt datasets in MsigDB were used as reference gene sets and GSEA analysis was performed according to default parameters [22]. The NOM $P$ value $<0.05$ was considered significant.

\section{Results}

Identification of DEGs

After differential analysis was performed by the "limma" $\mathrm{R}$ package with the threshold of $\mathrm{FDR}<0.05$ and $\left|\log _{2} \mathrm{FC}\right|>1$, the difference between $29 \mathrm{RP}$ papillary tissues and 33 normal papillary tissues were presented in a volcano plot (Fig. 2A). A total of 116 DEGs were identified, including 73 up-regulated DEGs and 43 down-regulated DEGs. The 100 most up-regulated or down-regulated DEGs were visualized in a heatmap (Fig. 2B).

\section{Construction of a weighted co-expression network and identification of hub modules}

The "WGCNA" package was applied to explore the gene expression profiles in $29 \mathrm{RP}$ papillary tissues and 33 normal papillary tissues. The samples were clustered hierarchically to remove outliers, but no samples were removed by the outliers check in this study (Fig. 3A). $\beta=7$ was selected as soft-thresholding power value to make the scale-free $R^{2}$ reach 0.9 and ensure a scalefree network (Fig. 3B). A total of 11 color modules were determined through average linkage clustering and dynamic tree cutting (Fig. 3C-D). The correlation between modules and clinical traits was presented in Fig. 3E, in which only the red module $(r=0.26$, $P=0.04)$ represented a significantly positive correlation

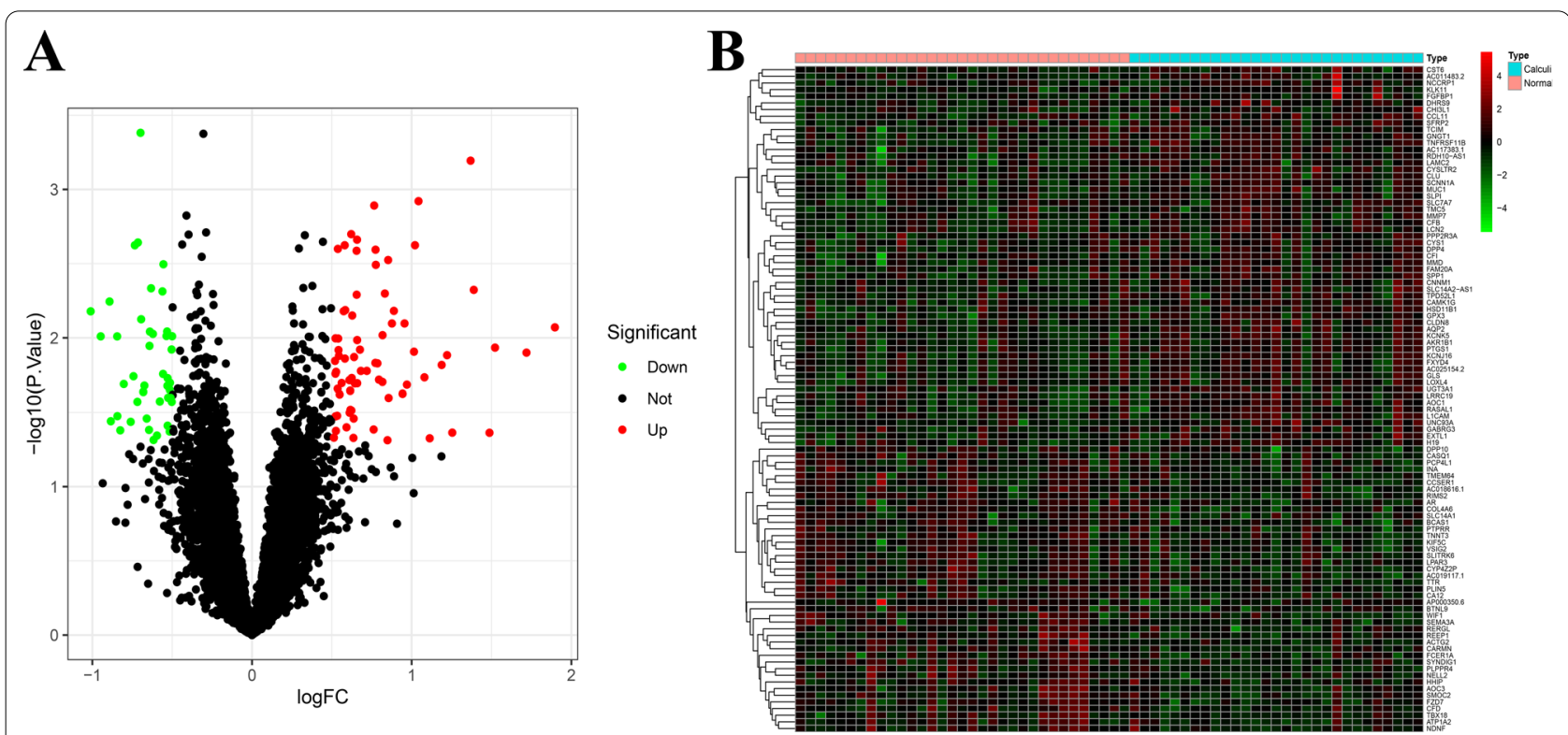

Fig. 2 Identification of DEGs in GSE73680. A Volcano plot of all DEGs. B Heatmap of the top 100 DEGs

(See figure on next page.)

Fig. 3 WGCNA for GSE73680. A Hierarchical clustering tree of 29 RP papillary tissues and 33 normal papillary tissues gene expression patterns. B Identification of power value. The red line represents R2 $>0.9$ when the power value $\beta$ is 7. C Module eigengene dendrogram presented the relationship of the modules generated by the clustering analysis. D Clustering dendrogram and merging of the gene co-expression modules. Each color represents one module. E Heatmap of the correlation between modules and clinical traits. The correlation coefficient and $P$ value between the module and clinical traits are shown at the row-column intersection. $\mathbf{F}$ Scatter plot of module eigengenes in the red module, which is positively correlated with KSD 


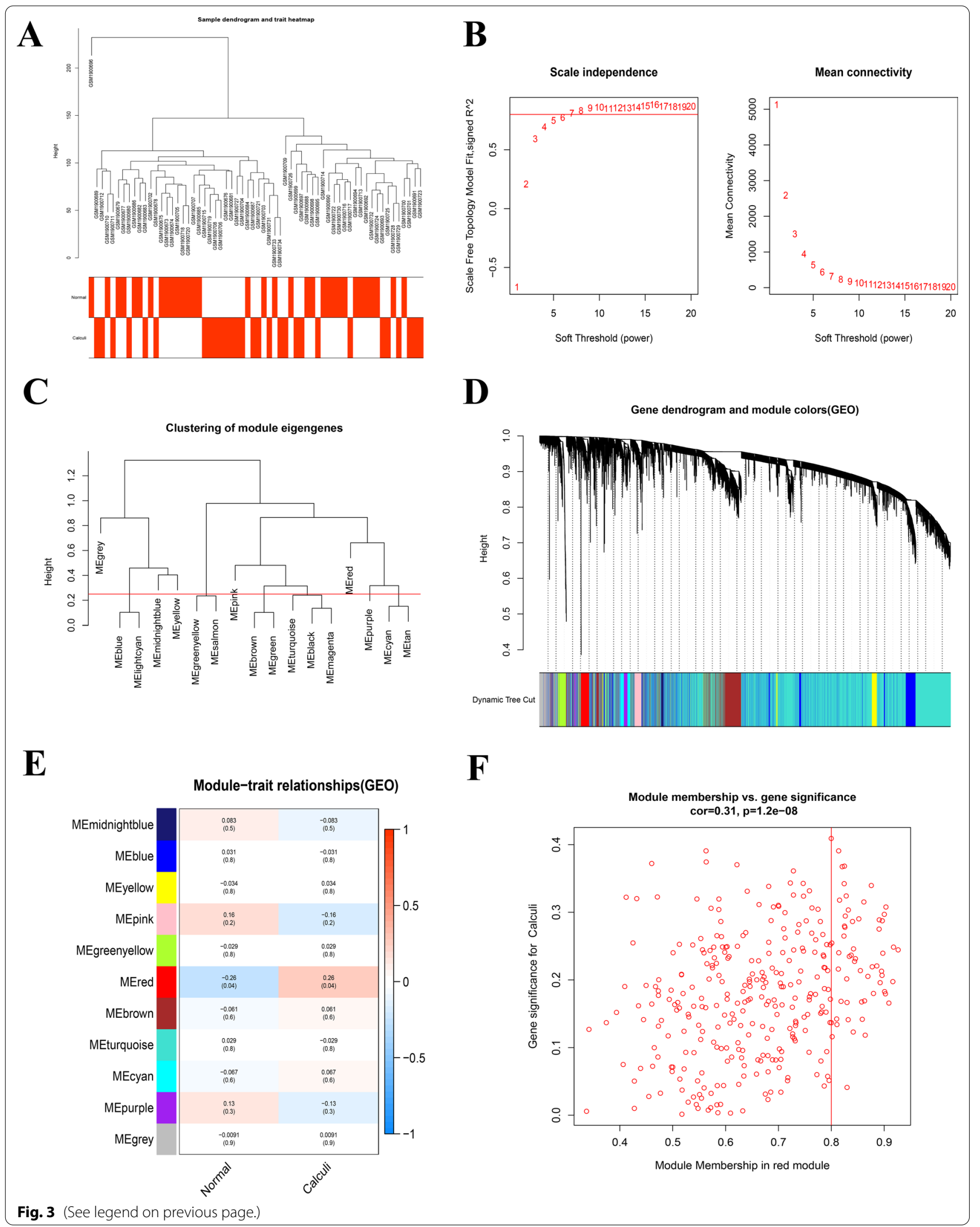


with stone disease. The number of genes contained in the red module is 324 and a significant correlation existed in the module membership and gene significance of the red module (Fig. 3F). Hence, the red module was selected as the key module for subsequent analysis.

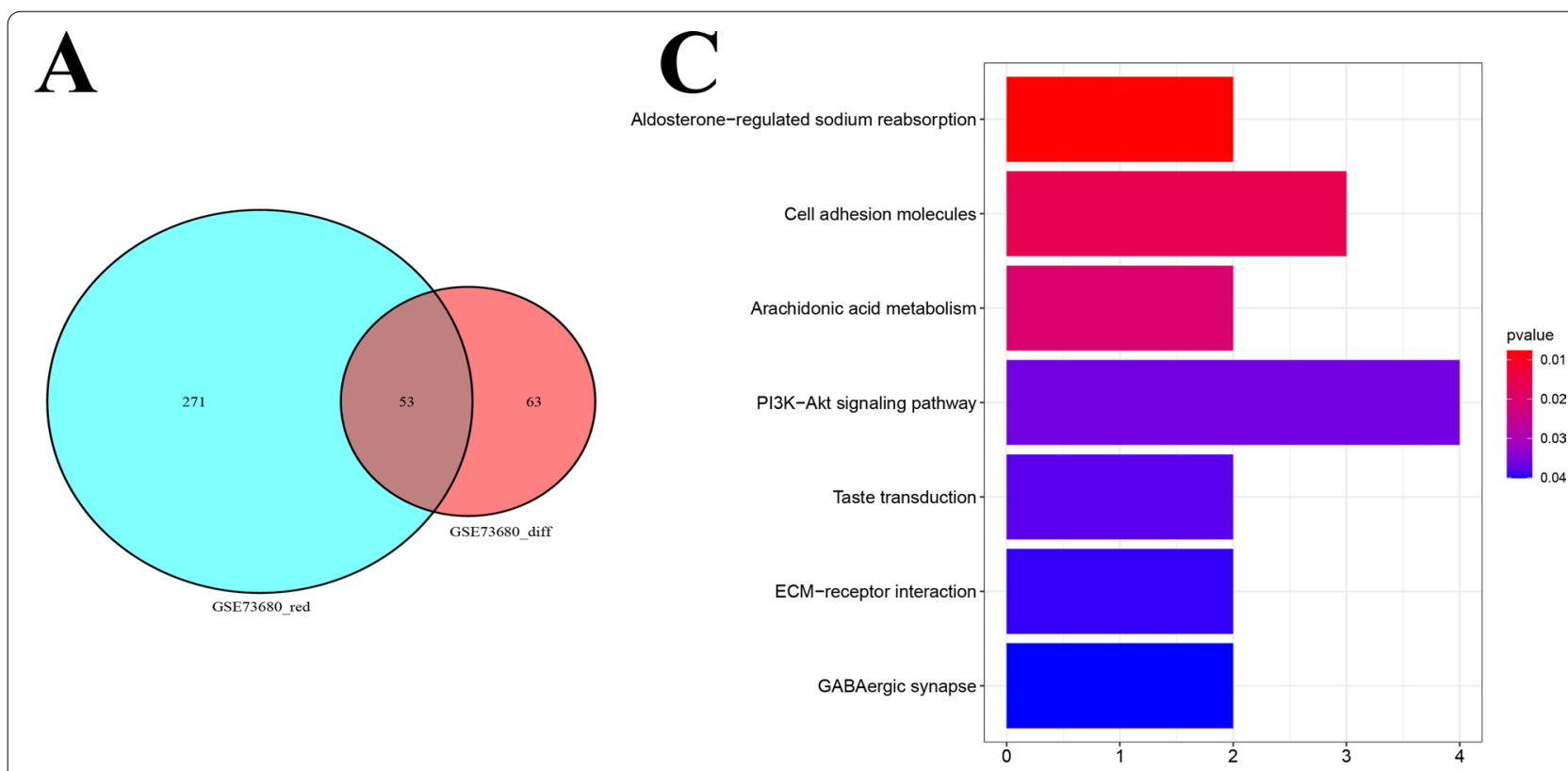

B

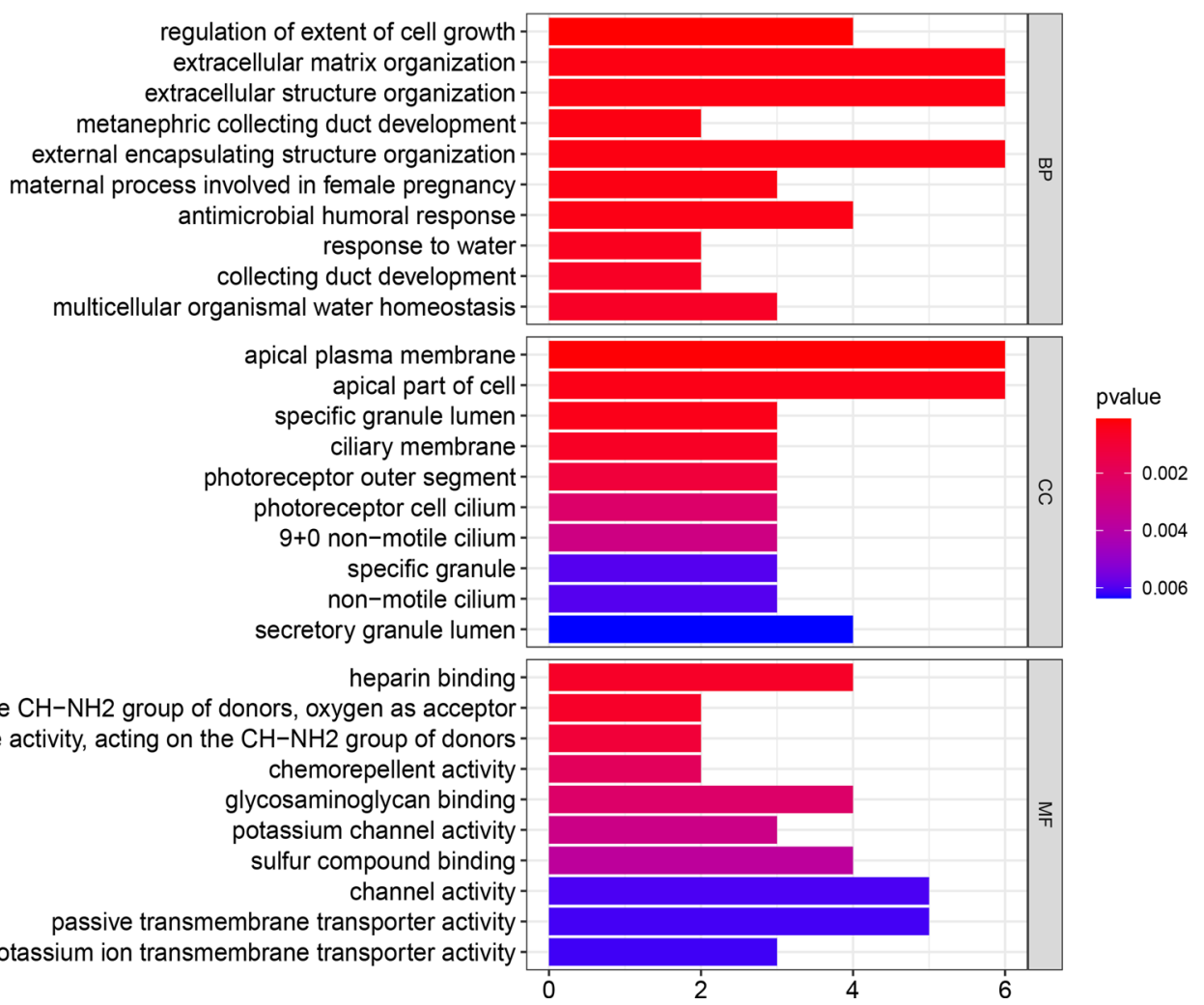

Fig. 4 Functional and pathway enrichment analysis. A Venn plot showing the intersection between DEGs and the genes in the red module, and 53 genes were obtained. $\mathbf{B}$ GO enrichment analysis of the obtained 53 genes. C KEGG analysis of the obtained 53 genes 


\section{Functional and pathway enrichment analysis}

53 genes were obtained by taking the intersection of DEGs and genes in the red module (Fig. 4A). The selected genes were studied through GO and KEGG enrichment analysis to explore the biological functions associated with stone disease. The results of GO enrichment analysis were presented in Fig. 4B. Among the biological processes (BP) analysis, these genes were associated with regulation of extent of cell growth, extracellular matrix (ECM) organization, and extracellular structure organization. The term of apical plasma membrane was enriched in cellular component (CC) analysis, while heparin binding was enriched in molecular function (MF) analysis. KEGG enrichment analysis results indicated that aldosterone-regulated sodium reabsorption, cell adhesion molecules, arachidonic acid (AA) metabolism, PI3K-Akt signaling pathway, and ECM-receptor interaction were associated with these genes (Fig. 4C).

\section{Construction of PPI network and identification of hub genes}

To further investigate the relationships among 53 genes at the protein level, the PPI network was constructed for candidate hub genes using Cytoscape according to STRING database. Up-regulated and down-regulated nodes were labeled with red and green, respectively (Fig. 5A). The top 30 genes with the largest number of adjacent nodes were screened as hub genes (28 up-regulated genes and 2 down-regulated genes), including SPP1, AQP2, DPP4, LCN2, MMP7, MUC1, SCNN1A, CLU, GPX3, PROM1, and so on (Fig. 5B). The detailed nodes and edges of the PPI network was listed in Additional file 2: Table S1.

\section{CIBERSORT analysis of immune infiltration}

CIBERSORT was performed to assess infiltrating levels of 22 immune cells in the RP papillary tissues and normal papillary tissues. The barplot displayed the relative composition ratio of 22 immune cells in all samples (Fig. 6A). Compared with control samples, RP papillary tissues harbored a higher proportion of macrophages $\mathrm{M} 0$, and the difference was statistically significant $(P=0.0093)$ (Fig. 6B). Correlation analysis showed that 21 up-regulated genes had a positive correlation with macrophages M0 and 2 down-regulated genes had a negative correlation with macrophages M0 (Fig. 6C).

\section{ssGSEA analysis of immune infiltration}

The ssGSEA method was also applied to quantify the immune infiltration and the enrichment levels of 27 immune cells and immune-related functions in samples were obtained (Fig. 7A). However, there was no statistical significance between the two groups. Still, correlation analysis showed that 9 up-regulated genes had a positive correlation with macrophages (Fig. 7B). Combined with two methods, 9 up-regulated genes were strongly positively related to macrophages infiltration, including SPP1, LCN2, MMP7, MUC1, SCNN1A, CLU, SLP1, LAMC2, CYSLTR2.

\section{GSEA analysis based on SPP1 expression}

$\mathrm{RP}$ papillary tissues were divided into two subgroups based on the median expression of SPP1. GTP metabolic process, histone methylation, positive regulation of Jun kinase (JNK) activity, protein K63-linked ubiquitination, ribosome binding were significantly enriched in the high-SPP1 subgroup, while negative regulation of IL-1 $\beta$
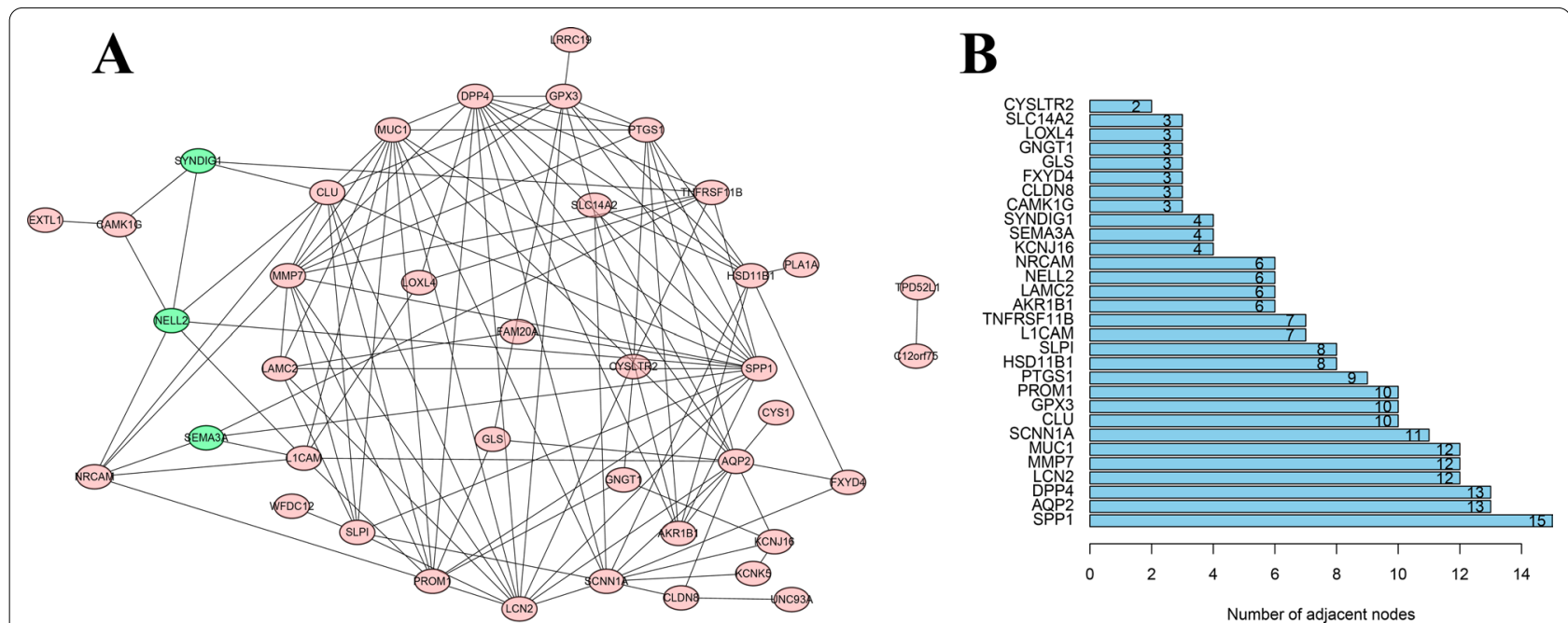

Fig. 5 PPI network construction. A The PPI network was drawn using Cytoscape, and the network nodes represent proteins (red: up-regulated proteins and blue: down-regulated proteins). B Histogram of key genes 


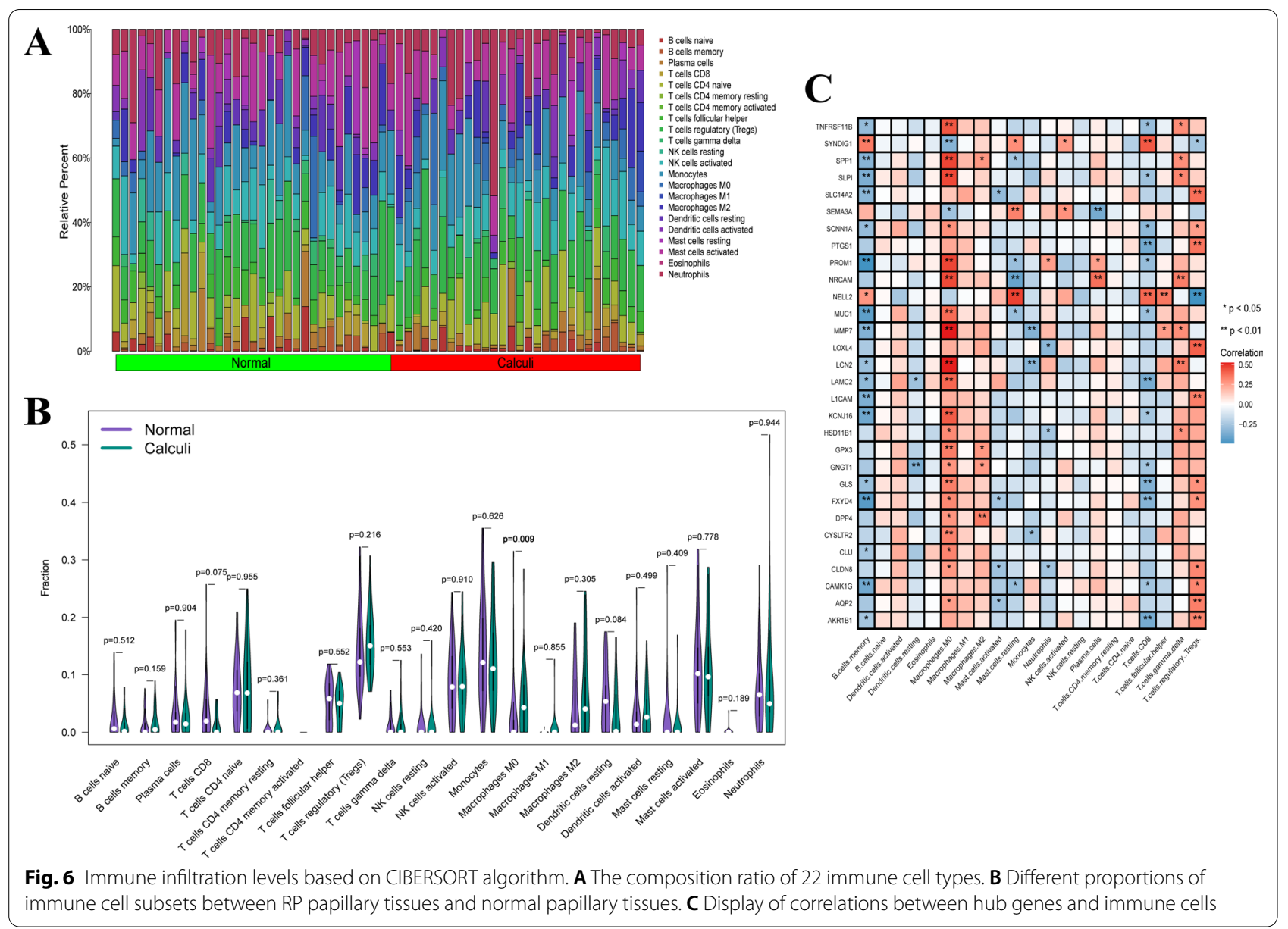

production, negative regulation of IL-1 production, and G-protein coupled receptor activity were enriched in the low-SPP1 subgroup (Fig. 8).

\section{Discussion}

The present study used multiple bioinformatic methods to identify KSD-related hub genes and explore the relationship between these genes and macrophage infiltration levels based on the GSE73680 dataset. A total of 116 DEGs were found by differential analysis. WGCNA was performed to construct a co-expression network and identify key modules associated with KSD, and the red module was selected as the key module. By taking the intersection of DEGs and genes in the red module, 53 genes were subjected to functional and pathway enrichment analyses and the PPI network construction. 30 hub genes were screened based on their numbers of adjacent nodes. By analyzing the immune characteristics of KSD patients via two algorithms, CIBERSORT analysis revealed a significantly increased proportion of M0 macrophages in RP tissues, while ssGSEA revealed no significant differences. Correlation analysis showed that SPP1, LCN2, MMP7, MUC1, SCNN1A, CLU, SLP1, LAMC2, and CYSLTR2 were positively correlated with macrophages infiltration. To our great interest, SPP1 had the highest number of edges and was selected as the top hub gene for further GSEA analysis.

GO enrichment analysis indicated that genes were enriched in ECM organization and extracellular structure organization. KEGG enrichment analysis suggested that genes were bound up with cell adhesion molecules and ECM-receptor interaction. Collagen is an important component of the ECM, and RPs consist of $\mathrm{CaP}$ crystals mixed with membrane-bound vesicles, collagen fibers, and other components of the ECM [23]. In RP theory, interstitial apatite deposits must grow outwards and reach the renal papillary surface to contact the pelvic urine for further $\mathrm{CaOx}$ deposition [24]. Such a breach must require the involvement of ECM and extracellular structure reconstruction and remodeling. Based on microscopic and analytical studies, Khan et al. first proposed that matrix vesicles promote $\mathrm{CaP}$ crystals 


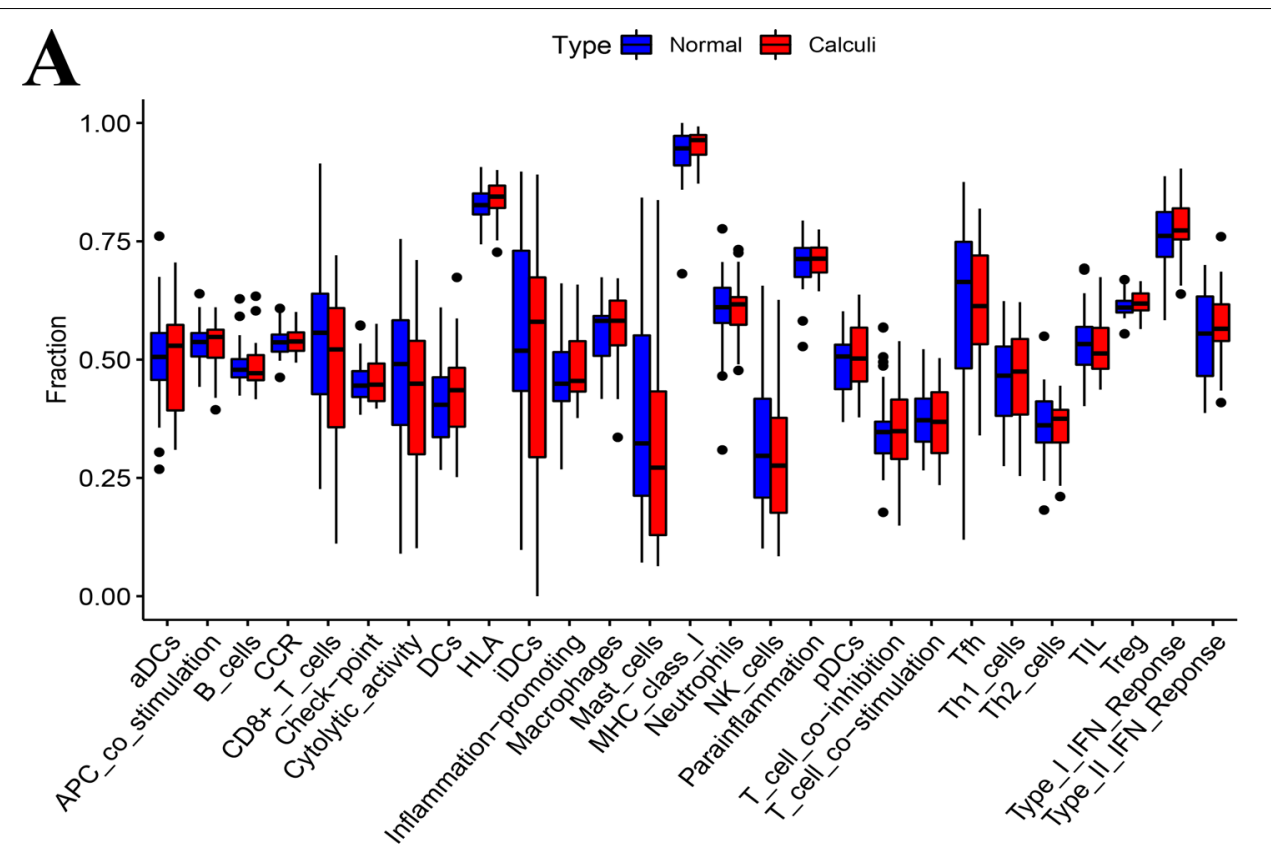

B

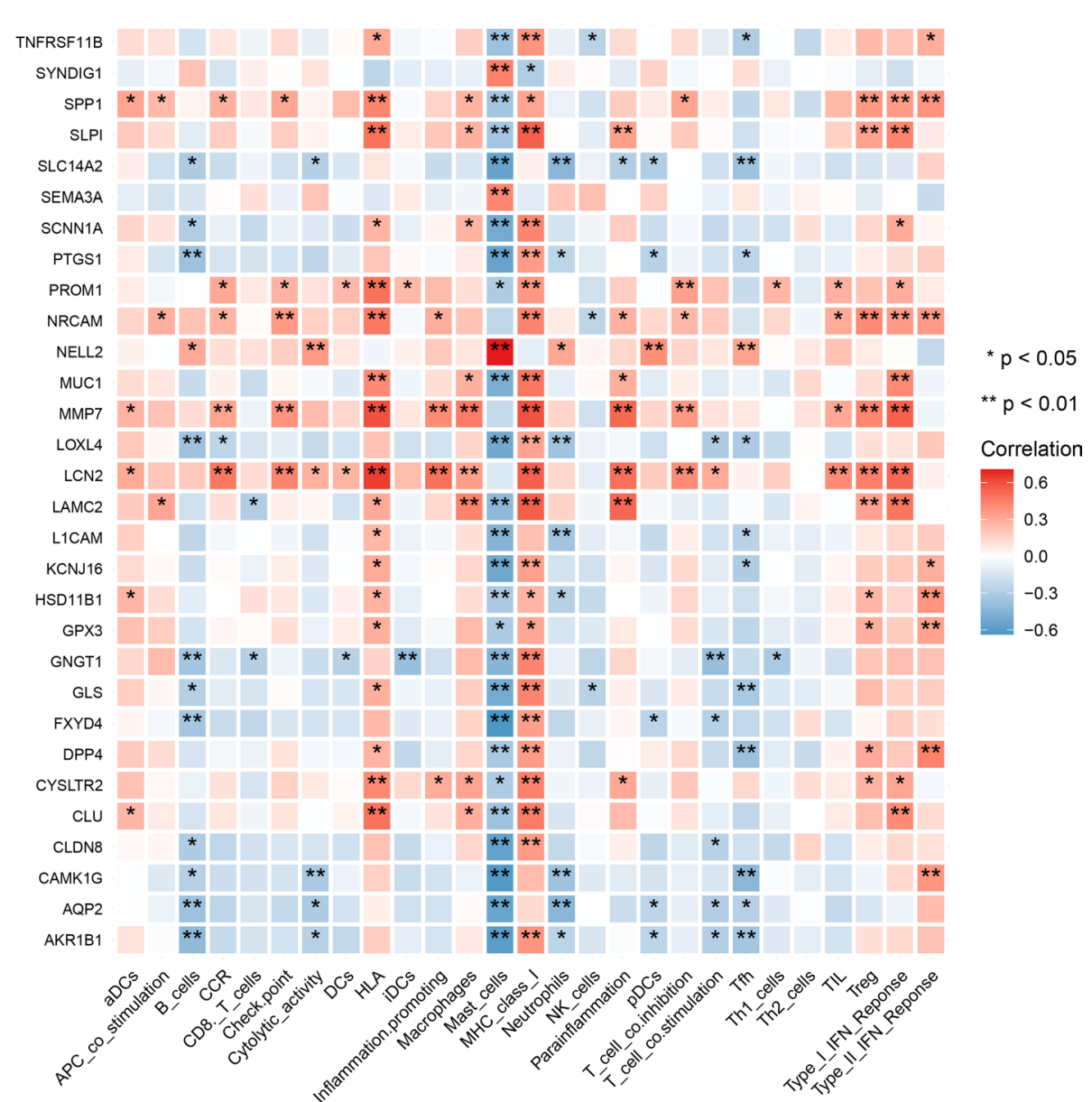

Fig. 7 Immune infiltration levels based on ssGSEA. A Different proportions of 27 immune cells and immune-related functions between RP papillary tissues and normal papillary tissues. B Display of correlations between hub genes and immune cells and immune-related functions 


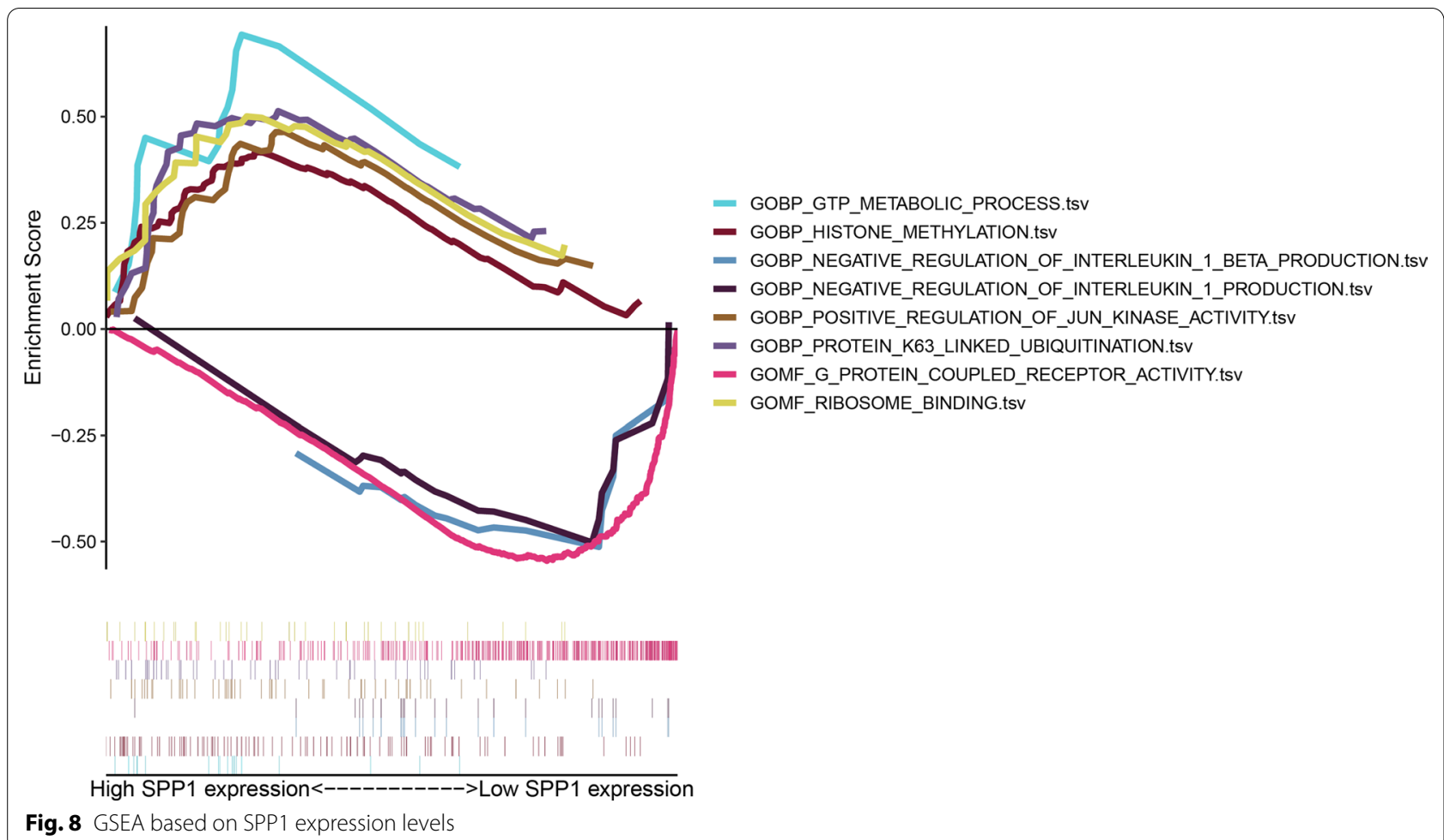

formation and these calcified deposits progress through the mineralization of collagen and other components of the ECM, leading to the expansion of RPs [23]. In addition, the pathway of aldosterone-regulated sodium reabsorption and AA metabolism were also significantly enriched. A recent study has revealed the influences of aldosterone and intra-vascular volume on calcium homeostasis and urinary calcium levels, suggesting the potential role of this pathway in KSD [25]. Baggio et al. found higher contents of AA and prostaglandin E2 (PGE2) in plasma, higher urinary calcium excretion, as well as intestinal calcium absorption in idiopathic calcium stone formers compared to healthy controls [26]. Increased AA may activate the intestinal and renal transport of oxalate to induce hyperoxaluria [27]. PGE2, a bioactive lipid generated from AA, could increase urinary calcium excretion by affecting renal tubular function and increasing intestinal calcium absorption [27]. Further studies are needed to clarify the potential implication of these pathways in KSD.

Water et al. first reported the infiltration of macrophages around the interstitial crystals in human kidney papillae [28]. Since then, a growing number of studies have confirmed the involvement of macrophages in stone formation and development, most of which have focused on the role of macrophages polarization. Generally, M0 macrophages can polarize into two main phenotypes, pro-inflammatory $\mathrm{M} 1$ phenotype and anti-inflammatory M2 phenotype, depending on local microenvironment [29]. In human kidney tissues, stone formers showed an increased gene expression associated with M1 phenotype and a decreased gene expression associated with M2 phenotype compared with controls [30]. Monocytes can be differentiated into $\mathrm{M} 1$ macrophages under $\mathrm{CaOx}$ crystals stimulation and M1 macrophages promote crystal deposition and accelerate stone development via enhancing tissue damage and renal inflammation [30-32]. By contrast, M2 macrophages are involved in the suppression of stone formation due to potent crystal phagocytic ability [30, 33, 34]. Thus, there has been an increasing interest in altering the macrophages phenotypes as therapeutic targets.

Given the importance of macrophages in KSD, immune infiltration was assessed in the dataset by applying two independent analytical methods. Although there were no statistically significant differences in $\mathrm{M} 1$ and $\mathrm{M} 2$ macrophages infiltration levels between the two groups, CIBERSORT analysis revealed that the proportion of M0 macrophages in RP papillary tissues was higher than that in normal papillary tissues. Non-polarized macrophages were designated as M0 phenotype. In vitro studies have demonstrated that M0 macrophages were able to internalize and eliminate COM crystals via phagocytosis [35, 36]. M0 macrophages could also affect the function of 
other cells. Zou et al. found that renal tubular epithelial cells (RTECs) showed increased COM crystal adhesion and induced more expression of inflammatory cytokines of SPP1, MCP-1, and TNF-a when they were co-cultured with M0 macrophages [37]. Exosomes derived from COM-treated M0 macrophages can stimulate IL-8 secretion from RTECs and monocytes, activate monocytes and neutrophils migration, and enhance macrophages phagocytic activity [38, 39]. Moreover, these exosomes have higher binding capacity to COM crystals due to exosomal membrane fragility, which helps crystal invasion through ECM in the renal interstitium [38]. Our results further confirmed that macrophages serve an important role during the stone formation process.

PPI network was constructed and 30 genes were selected as hub genes according to their numbers of adjacent nodes. Furthermore, 9 hub genes were strongly positively related to macrophages infiltration based on two methods, including SPP1, LCN2, MMP7, MUC1, SCNN1A, CLU, SLP1, LAMC2, CYSLTR2. SPP1 had the highest number of edges and was chosen as the top hub gene. In the human kidneys, SPP1 is expressed in the thick ascending limbs of the loop of Henle, collecting ducts, and urine [40]. Some studies have reported decreased urinary excretion of SPP1 in stone formers than controls [41, 42], while others showed increased excretion or no difference [43, 44]. Still, SPP1 is identified as one of the most important organic matrix components in calcium stones and numerous studies showed that SPP1 expression was increased in animal models [45]. In vitro studies found that SSP1 was able to inhibit $\mathrm{CaOx}$ crystal nucleation, growth, and aggregation [46-48]. However, the role of SPP1 in crystal adhesion is controversial. Wesson et al. observed that SPP1 might favor $\mathrm{CaOx}$ dehydrate (COD) formation rather than $\mathrm{CaOx}$ monohydrate (COM), and COD is less adherent to RTECs, which could reduce crystal attachment [49]. By contrast, Yamate et al. considered SPP1 as a promoter of stone formation because of increased crystal adhesion and deposition in its presence [50-52]. The reason for two completely different actions may lie in the fact that SPP1 has two forms: free and immobilized SPP1 play inhibitory and supportive roles in stone formation, respectively [53]. Notably, it has been reported that some polymorphisms in the OPN gene may predispose to stone disease $[54,55]$. In addition, SPP1 is a significant chemical attractant for macrophages, dendritic cells, and T cells. RTECs stimulated by crystal deposition could secrete SPP1 to induce macrophage migration and phagocytosis [56].

GSEA analysis showed that positive regulation of JNK activity was significantly enriched in the high-SPP1 subgroup. Several studies have demonstrated that the JNK pathway was activated in RTECs after high oxalate or calcium exposure and activation of the JNK pathway could induce SPP1 expression and crystal deposition $[53,57,58]$. This is also supported by our results. In addition, negative regulation of IL- $1 \beta$ production was significantly enriched in the low-SPP1 subgroup. Mulay et al. have found that $\mathrm{CaOx}$ crystals could activate intrarenal dendritic cells to secrete IL- $1 \beta$ via the NLRP3 inflammasome pathway and lead to renal damage [59]. Hence, IL-1 $\beta$ production might aggravate the progression of KSD. The low-SPP1 subgroup may have a lower infiltration of immune cells, which leads to a decreased production of IL-1 $\beta$ and attenuation of kidney injury.

In this study, the key modules and hub genes related to KSD were screened, their biological functions and pathways were identified, and the associations between hub genes and macrophages were also studied, which shed light on the potential pathogenic mechanism of KSD and present an avenue for therapeutic exploration. Specifically, the findings suggest that SPP1 plays a pivotal role in KSD and the interaction between SPP1 and macrophages may be crucial for stone formation. Therefore, SPP1 could serve as a biomarker for the early diagnosis and a target for the treatment of KSD, and inhibition of SPP1 might modulate the phenotype of macrophages to protect against stone formation.

This study has some limitations. First, there are few datasets about KSD in GEO database. Thus, an external validation set to verify the accuracy is missing. Second, in vivo and in vitro studies need to be conducted to investigate potential mechanisms of real hub genes and macrophages for future clinical translation.

\section{Conclusion}

Our research uses WGCNA, combined with immune infiltration analysis and correlation analysis to identify the hub genes in KSD, which provides further insights into potential therapeutic targets for KSD. As the top hub gene, SPP1 is widely connected with other hub genes, and a great number of studies have confirmed the role of SPP1 in stone formation and development. However, additional studies are needed to elucidate the role the interactions between SPP1 and macrophages play in KSD.

\section{Abbreviations}

KSD: Kidney stone disease; DEGs: Differentially expressed genes; WGCNA: Weighted gene co-expression network analysis; GO: Gene Ontology; KEGG: Kyoto Encyclopedia of Genes and Genomes; PPI: Protein-protein interaction CaOx: Calcium oxalate; CaP: Calcium phosphate; RP: Randall's plaque; GSEA: Gene set enrichment analysis; ssGSEA: Single sample gene set enrichment 
analysis; BP: Biological processes; CC: Cellular component; MF: Molecular function; COM: Calcium oxalate monohydrate; COD: Calcium oxalate dehydrate; RTECs: Renal tubular epithelial cells; FDR: False discovery rate; FC: Fold change; TOM: Topological overlap measure; ECM: Extracellular matrix; JNK: Jun kinase; AA: Arachidonic acid.

\section{Supplementary Information}

The online version contains supplementary material available at https://doi. org/10.1186/s12920-022-01157-4.

Additional file 1. Code used to perform the multiple bioinformatic analysis.

Additional file 2. Detailed nodes and edges of the PPI network.

\section{Acknowledgements}

We thank all developers of the R programming packages, public databases and softwares.

\section{Authors' contributions}

HSY, XQD, XY, and WSG contributed to the design, analysis, and interpretation of data; drafting of the manuscript; and critical revision of the manuscript. XQD and XJZ contributed to the statistical analysis. HSY, XQD, XJZ, LCQ, SJX, XY, and WSG contributed to the methodology. LCQ, SJX, XY, and WSG contributed to the project administration. HSY, and XQD wrote the manuscript. All authors read and approved the final manuscript.

\section{Funding}

Not applicable.

\section{Availability of data and materials}

All raw and processed data are freely available from GEO database (https:// www.ncbi.nlm.nih.gov/geo/)

\section{Declarations}

\section{Ethics approval and consent to participate}

Not applicable.

\section{Consent for publication}

Not applicable.

\section{Competing interests}

The authors declare that they have no competing interests.

Received: 12 November 2021 Accepted: 6 January 2022

Published online: 11 January 2022

\section{References}

1. Khan SR, Pearle MS, Robertson WG, Gambaro G, Canales BK, Doizi S, Traxer O, Tiselius HG. Kidney stones. Nat Rev Dis Primers. 2016;2:16008.

2. D'Costa MR, Haley WE, Mara KC, Enders FT, Vrtiska TJ, Pais VM, Jacobsen SJ, McCollough CH, Lieske JC, Rule AD. Symptomatic and radiographic manifestations of kidney stone recurrence and their prediction by risk factors: a prospective cohort study. J Am Soc Nephrol. 2019;30(7):1251-60.

3. Sorokin I, Mamoulakis C, Miyazawa K, Rodgers A, Talati J, Lotan Y. Epidemiology of stone disease across the world. World J Urol. 2017:35(9):1301-20.

4. Kusmartsev S, Dominguez-Gutierrez PR, Canales BK, Bird VG, Vieweg J, Khan SR. Calcium oxalate stone fragment and crystal phagocytosis by human macrophages. J Urol. 2016;195(4 Pt 1):1143-51.

5. Randall A. The origin and growth of renal calculi. Ann Surg. 1937;105(6):1009-27.

6. Evan AP, Lingeman JE, Coe FL, Parks JH, Bledsoe SB, Shao Y, Sommer AJ, Paterson RF, Kuo RL, Grynpas M. Randall's plaque of patients with nephrolithiasis begins in basement membranes of thin loops of Henle. J Clin Investig. 2003;111(5):607-16.
7. Arcidiacono T, Mingione A, Macrina L, Pivari F, Soldati L, Vezzoli G. Idiopathic calcium nephrolithiasis: a review of pathogenic mechanisms in the light of genetic studies. Am J Nephrol. 2014;40(6):499-506.

8. Kaleta B. The role of osteopontin in kidney diseases. Inflamm Res. 2019:68(2):93-102.

9. Gericke A, Qin C, Spevak L, Fujimoto Y, Butler WT, Sørensen ES, Boskey AL. Importance of phosphorylation for osteopontin regulation of biomineralization. Calcif Tissue Int. 2005;77(1):45-54.

10. Hunter GK. Role of osteopontin in modulation of hydroxyapatite formation. Calcif Tissue Int. 2013;93(4):348-54.

11. Taguchi K, Okada A, Unno R, Hamamoto S, Yasui T. Macrophage function in calcium oxalate kidney stone formation: a systematic review of literature. Front Immunol. 2021;12:673690.

12. Taguchi K, Hamamoto S, Okada A, Unno R, Kamisawa H, Naiki T, Ando R, Mizuno K, Kawai N, Tozawa K, et al. Genome-wide gene expression profiling of Randall's plaques in calcium oxalate stone formers. J Am Soc Nephrol. 2017;28(1):333-47

13. Ritchie ME, Phipson B, Wu D, Hu Y, Law CW, Shi W, Smyth GK. limma powers differential expression analyses for RNA-sequencing and microarray studies. Nucleic Acids Res. 2015:43(7):e47.

14. Langfelder P, Horvath S. WGCNA: an R package for weighted correlation network analysis. BMC Bioinform. 2008;9:559.

15. Yip AM, Horvath S. Gene network interconnectedness and the generalized topological overlap measure. BMC Bioinform. 2007;8:22.

16. Ravasz E, Somera AL, Mongru DA, Oltvai ZN, Barabási AL. Hierarchical organization of modularity in metabolic networks. Science. 2002;297(5586):1551-5.

17. Ashburner M, Ball CA, Blake JA, Botstein D, Butler H, Cherry JM, Davis AP, Dolinski K, Dwight SS, Eppig JT, et al. Gene ontology: tool for the unification of biology. The Gene Ontology Consortium. Nat Genet. 2000:25(1):25-9.

18. Kanehisa M, Goto S. KEGG: kyoto encyclopedia of genes and genomes. Nucleic Acids Res. 2000;28(1):27-30.

19. Newman AM, Liu CL, Green MR, Gentles AJ, Feng W, Xu Y, Hoang CD, Diehn M, Alizadeh AA. Robust enumeration of cell subsets from tissue expression profiles. Nat Methods. 2015;12(5):453-7.

20. Barbie DA, Tamayo P, Boehm JS, Kim SY, Moody SE, Dunn IF, Schinzel AC, Sandy P, Meylan E, Scholl C, et al. Systematic RNA interference reveals that oncogenic KRAS-driven cancers require TBK1. Nature. 2009:462(7269):108-12.

21. Subramanian A, Tamayo P, Mootha VK, Mukherjee S, Ebert BL, Gillette MA, Paulovich A, Pomeroy SL, Golub TR, Lander ES, et al. Gene set enrichment analysis: a knowledge-based approach for interpreting genome-wide expression profiles. Proc Natl Acad Sci U S A. 2005;102(43):15545-50.

22. Liberzon A, Birger C, Thorvaldsdóttir H, Ghandi M, Mesirov JP, Tamayo P. The molecular signatures database (MSigDB) hallmark gene set collection. Cell Syst. 2015;1(6):417-25.

23. Khan SR, Rodriguez DE, Gower LB, Monga M. Association of Randall plaque with collagen fibers and membrane vesicles. J Urol. 2012;187(3):1094-100.

24. Coe FL, Evan AP, Worcester EM, Lingeman JE. Three pathways for human kidney stone formation. Urol Res. 2010;38(3):147-60.

25. Bayomy O, Zaheer S, Williams JS, Curhan G, Vaidya A. Disentangling the relationships between the renin-angiotensin-aldosterone system, calcium physiology, and risk for kidney stones. J Clin Endocrinol Metab. 2020;105(6):1937-46

26. Baggio B, Budakovic A, Nassuato MA, Vezzoli G, Manzato E, Luisetto G, Zaninotto M. Plasma phospholipid arachidonic acid content and calcium metabolism in idiopathic calcium nephrolithiasis. Kidney Int. 2000:58(3):1278-84

27. Baggio B, Gambaro G, Zambon S, Marchini F, Bassi A, Bordin L, Clari G, Manzato E. Anomalous phospholipid n-6 polyunsaturated fatty acid composition in idiopathic calcium nephrolithiasis. J Am Soc Nephrol. 1996:7(4):613-20.

28. de Water R, Noordermeer C, van der Kwast TH, Nizze H, Boevé ER, Kok DJ, Schröder FH. Calcium oxalate nephrolithiasis: effect of renal crystal deposition on the cellular composition of the renal interstitium. Am J Kidney Dis. 1999:33(4):761-71.

29. Murray PJ. Macrophage polarization. Annu Rev Physiol. 2017;79:541-66. 
30. Taguchi K, Okada A, Hamamoto S, Unno R, Moritoki Y, Ando R, Mizuno K, Tozawa K, Kohri K, Yasui T. M1/M2-macrophage phenotypes regulate renal calcium oxalate crystal development. Sci Rep. 2016;6:35167.

31. Taguchi K, Okada A, Hamamoto S, Iwatsuki S, Naiki T, Ando R, Mizuno K, Tozawa K, Kohri K, Yasui T. Proinflammatory and metabolic changes facilitate renal crystal deposition in an obese mouse model of metabolic syndrome. J Urol. 2015;194(6):1787-96.

32. Dominguez-Gutierrez PR, Kusmartsev S, Canales BK, Khan SR. Calcium oxalate differentiates human monocytes into inflammatory M1 macrophages. Front Immunol. 2018;9:1863

33. Taguchi K, Okada A, Kitamura H, Yasui T, Naiki T, Hamamoto S, Ando R, Mizuno K, Kawai N, Tozawa K, et al. Colony-stimulating factor-1 signaling suppresses renal crystal formation. J Am Soc Nephrol. 2014;25(8):1680-97.

34. Anders HJ, Suarez-Alvarez B, Grigorescu M, Foresto-Neto O, Steiger S, Desai J, Marschner JA, Honarpisheh M, Shi C, Jordan J, et al. The macrophage phenotype and inflammasome component NLRP3 contributes to nephrocalcinosis-related chronic kidney disease independent from IL-1-mediated tissue injury. Kidney Int. 2018;93(3):656-69.

35. de Water R, Leenen PJ, Noordermeer C, Nigg AL, Houtsmuller AB, Kok DJ, Schröder $\mathrm{FH}$. Cytokine production induced by binding and processing of calcium oxalate crystals in cultured macrophages. Am J Kidney Dis. 2001;38(2):331-8.

36. Okada A, Aoki H, Onozato D, Kato T, Hashita T, Takase H, Sugino T, Unno R, Taguchi K, Hamamoto S, et al. Active phagocytosis and diachronic processing of calcium oxalate monohydrate crystals in an in vitro macrophage model. Kidney Blood Press Res. 2019:44(5):1014-25.

37. Zuo L, Tozawa K, Okada A, Yasui T, Taguchi K, Ito Y, Hirose Y, Fujii Y, Niimi K, Hamamoto S, et al. A paracrine mechanism involving renal tubular cells, adipocytes and macrophages promotes kidney stone formation in a simulated metabolic syndrome environment. J Urol. 2014;191(6):1906-12.

38. Singhto $\mathrm{N}$, Thongboonkerd $\mathrm{V}$. Exosomes derived from calcium oxalateexposed macrophages enhance IL-8 production from renal cells, neutrophil migration and crystal invasion through extracellular matrix. J Proteomics. 2018:185:64-76.

39. Singhto N, Kanlaya R, Nilnumkhum A, Thongboonkerd V. Roles of macrophage exosomes in immune response to calcium oxalate monohydrate crystals. Front Immunol. 2018;9:316.

40. Hudkins KL, Giachelli CM, Cui Y, Couser WG, Johnson RJ, Alpers CE. Osteopontin expression in fetal and mature human kidney. J Am Soc Nephrol. 1999;10(3):444-57.

41. Yasui T, Fujita K, Hayashi Y, Ueda K, Kon S, Maeda M, Uede T, Kohri K. Quantification of osteopontin in the urine of healthy and stone-forming men. Urol Res. 1999;27(4):225-30.

42. Icer MA, Gezmen-Karadag M, Sozen S. Can urine osteopontin levels, which may be correlated with nutrition intake and body composition, be used as a new biomarker in the diagnosis of nephrolithiasis? Clin Biochem. 2018;60:38-43.

43. Tsuji H, Tohru U, Hirotsugu U, Masanori I, Yuji H, Takashi K. Urinary concentration of osteopontin and association with urinary supersaturation and crystal formation. Int J Urol. 2007;14(7):630-4.

44. Anan G, Yoneyama T, Noro D, Tobisawa Y, Hatakeyama S, Sutoh Yoneyama $\mathrm{M}$, Yamamoto $\mathrm{H}$, Imai A, Iwamura $\mathrm{H}$, Kohada $\mathrm{Y}$, et al. The impact of glycosylation of osteopontin on urinary stone formation. Int J Mol Sci. 2019;21(1):93.

45. Aggarwal KP, Narula S, Kakkar M, Tandon C. Nephrolithiasis: molecular mechanism of renal stone formation and the critical role played by modulators. Biomed Res Int. 2013;2013:292953.

46. Hoyer JR, Otvos L Jr, Urge L. Osteopontin in urinary stone formation. Ann NY Acad Sci. 1995;760:257-65.

47. Shiraga H, Min W, VanDusen WJ, Clayman MD, Miner D, Terrell CH, Sherbotie JR, Foreman JW, Przysiecki C, Neilson EG, et al. Inhibition of calcium oxalate crystal growth in vitro by uropontin: another member of the aspartic acid-rich protein superfamily. Proc Natl Acad Sci U S A 1992;89(1):426-30.

48. Worcester EM, Beshensky AM. Osteopontin inhibits nucleation of calcium oxalate crystals. Ann N Y Acad Sci. 1995;760:375-7.

49. Wesson JA, Worcester EM, Wiessner JH, Mandel NS, Kleinman JG. Control of calcium oxalate crystal structure and cell adherence by urinary macromolecules. Kidney Int. 1998;53(4):952-7.
50. Yamate T, Kohri K, Umekawa T, Iguchi M, Kurita T. Osteopontin antisense oligonucleotide inhibits adhesion of calcium oxalate crystals in MadinDarby canine kidney cell. J Urol. 1998;160(4):1506-12.

51. Yamate T, Kohri K, Umekawa T, Konya E, Ishikawa Y, Iguchi M, Kurita T. Interaction between osteopontin on madin darby canine kidney cell membrane and calcium oxalate crystal. Urol Int. 1999;62(2):81-6.

52. Yamate T, Kohri K, Umekawa T, Amasaki N, Amasaki N, Isikawa Y, Iguchi M, Kurita T. The effect of osteopontin on the adhesion of calcium oxalate crystals to Madin-Darby canine kidney cells. Eur Urol. 1996;30(3):388-93.

53. Khan SR. Reactive oxygen species as the molecular modulators of calcium oxalate kidney stone formation: evidence from clinical and experimental investigations. J Urol. 2013;189(3):803-11.

54. Safarinejad MR, Shafiei N, Safarinejad S. Association between polymorphisms in osteopontin gene (SPP1) and first episode calcium oxalate urolithiasis. Urolithiasis. 2013;41(4):303-13.

55. Gao B, Yasui T, Itoh Y, Li Z, Okada A, Tozawa K, Hayashi Y, Kohri K. Association of osteopontin gene haplotypes with nephrolithiasis. Kidney Int. 2007;72(5):592-8

56. Okada A, Yasui T, Fujii Y, Niimi K, Hamamoto S, Hirose M, Kojima Y, Itoh $Y$, Tozawa K, Hayashi Y, et al. Renal macrophage migration and crystal phagocytosis via inflammatory-related gene expression during kidney stone formation and elimination in mice: detection by association analysis of stone-related gene expression and microstructural observation. J Bone Miner Res. 2010;25(12):2701-11.

57. Chaturvedi LS, Koul S, Sekhon A, Bhandari A, Menon M, Koul HK. Oxalate selectively activates p38 mitogen-activated protein kinase and c-Jun $\mathrm{N}$-terminal kinase signal transduction pathways in renal epithelial cells. J Biol Chem. 2002;277(15):13321-30.

58. Xun Y, Zhou P, Yang Y, Li C, Zhang J, Hu H, Qin B, Zhang Z, Wang Q, Lu Y, et al. Role of Nox4 in high calcium-induced renal oxidative stress damage and crystal deposition. Antioxid Redox Signal. 2021.

59. Mulay SR, Kulkarni OP, Rupanagudi KV, Migliorini A, Darisipudi MN, Vilaysane A, Muruve D, Shi Y, Munro F, Liapis H, et al. Calcium oxalate crystals induce renal inflammation by NLRP3-mediated IL-1 $\beta$ secretion. J Clin Investig. 2013;123(1):236-46.

\section{Publisher's Note}

Springer Nature remains neutral with regard to jurisdictional claims in published maps and institutional affiliations.

Ready to submit your research? Choose BMC and benefit from

- fast, convenient online submission

- thorough peer review by experienced researchers in your field

- rapid publication on acceptance

- support for research data, including large and complex data types

- gold Open Access which fosters wider collaboration and increased citations

- maximum visibility for your research: over 100M website views per year

At BMC, research is always in progress.

Learn more biomedcentral.com/submissions 